\title{
Brucellosis: Community, medical and veterinary workers' knowledge, attitudes, and practices in Northern Uganda
}

Harriet Muloki Nabirye ${ }^{1,4}$, Joseph Erume ${ }^{2}$, George William Nasinyama ${ }^{1}$, Joseph Morison Kungu ${ }^{5}$, Jesca Nakavuma ${ }^{2}$, Duncan Ongeng ${ }^{4}$ and David Okello Owiny ${ }^{3}$

1. Department of Biosecurity, Ecosystems and Veterinary Public Health, College of Veterinary Medicine, Animal Resources and Biosecurity, Makerere University, P.O. Box 7062 Kampala, Uganda; 2. Department of Biomolecular Resources and Biolab Sciences, College of Veterinary Medicine, Animal Resources and Biosecurity, Makerere University, P.O. Box 7062 Kampala, Uganda; 3. Department of Biotechnical and Diagnostic Sciences, College of Veterinary Medicine, Animal Resources and Biosecurity, Makerere University, P.O. Box 7062 Kampala, Uganda; 4. Department of Animal Production and Range Management, Faculty of Agriculture and Environment, Gulu University. P. O. Box 166, Gulu, Uganda; 5. Department of Livestock Health, National Livestock Resources Research Institute, P. O. Box 96, Tororo, Uganda. Corresponding author: David Okello Owiny, e-mail: owinyd@gmail.com,

Co-authors: HMN: n.h.muloki@gu.ac.ug, JE: erujoseph@yahoo.com, GWN: gwnasinyama@gmail.com, JMK: kungu@live.com,JN: jesca.nakavuma@gmail.com,DO: duncanongeng@hotmail.com, DOO: owinyd@gmail.com Received: 15-02-2017, Accepted: 12-04-2017, Published online: 05-05-2017

doi: 10.14202/IJOH.2017.12-18 How to cite this article: Nabirye HM, Erume J, Nasinyama GW, Kungu JM, Nakavuma J, Ongeng D, Owiny DO (2017) Brucellosis: Community, medical and veterinary workers' knowledge, attitudes, and practices in Northern Uganda, Int J One Health 2017;3:12-18.

\begin{abstract}
Aim: This study aimed at determining the knowledge, attitudes, and practices of the community, medical and veterinary workers regarding brucellosis.

Materials and Methods: A cross-sectional study was conducted at selected health facilities in Apac, Gulu, Lira, and Pader districts of Northern Uganda using a standardized questionnaire. A total of 251 patients testing positive for brucellosis using the Brucella plate agglutination test, 59 medical and 29 veterinary workers were studied. Chi-square test at $95 \%$ confidence level was used to analyze data.

Results: Only $8 \%$ patients, $15.3 \%$ medical, and $21.4 \%$ veterinary workers were knowledgeable on transmission methods and symptoms for brucellosis and knowledge differed according to the level of education among patients $(\mathrm{p}=0.001)$, medical $(\mathrm{p}=0.001)$, and veterinary workers $(\mathrm{p}=0.012)$. Over $80 \%$ patients, medical and veterinary workers had a positive attitude. Only $8 \%$ patients, $13.6 \%$ medical, and $7.1 \%$ veterinary workers had good practices regarding brucellosis control.

Conclusion: Poor knowledge, poor practices, and positive attitude provide an opportunity for health education and policy formulation for the control of brucellosis. The prevalence studies of human and animal brucellosis are recommended to determine the magnitude of the problem.
\end{abstract}

Keywords: awareness, Brucellosis, patients, practitioners, Uganda.

\section{Introduction}

Brucellosis is a widespread zoonosis and has a great importance as a foodborne disease [1,2]. The disease often persists in the poorest and most vulnerable populations [3]. Brucellosis is a disease caused by bacteria belonging to the Brucella genus with six pathogenic species of which four including Brucella melitensis, Brucella suis, Brucella abortus, and Brucella canis are known to cause human disease [4-6]. Animals are the principal reservoirs of brucellosis and transmission to humans is by direct or indirect contact with infected animals or their products [7]. Human brucellosis affects any organ of the body with nonspecific symptoms and complications

Copyright: Nabirye, et al. This article is an open access article distributed under the terms of the Creative Commons Attribution 4.0 International License (http://creativecommons.org/licenses/ by/4.0/), which permits unrestricted use, distribution, and reproduction in any medium, provided you give appropriate credit to the original author(s) and the source, provide a link to the Creative Commons license, and indicate if changes were made. The Creative Commons Public Domain Dedication waiver (http:// creativecommons.org/ publicdomain/zero/1.0/) applies to the data made available in this article, unless otherwise stated. which are very diverse depending on the site of infection [4]. Diagnosing brucellosis can be problematic to a clinician who is unaware of the disease due to overlapping clinical manifestations and very often results into misdiagnosis [8]. Control of animal brucellosis results to a significant decline in human brucellosis [9]. Effective control requires adequate knowledge of causes, mode of transmission, signs and symptoms, as well as good attitudes and practices relating to the disease $[10,11]$. However, inadequate policies, funds, and awareness of the disease impose serious challenges [12].

Brucellosis widely occurs in Uganda and case reports of human disease with complications are on the increase [13-16]. Studies focusing on community awareness and perceptions about brucellosis have been conducted, but none has described the knowledge, attitudes, and practices of medical and veterinary workers in Uganda [15,16]. Knowledge, attitudes, and practices are critical in brucellosis prevention and control [11]. Good knowledge of transmission routes for brucellosis has a protective effect for human brucellosis infection [17]. Involving both medical and 
veterinary sectors provide opportunities for collaboration in dealing with brucellosis in endemic countries such as Uganda and awareness among clinicians aid rapid diagnosis $[18,19]$.

Without deliberate efforts to create awareness of brucellosis among the community, medical and veterinary workers who are key actors, incidences of the disease in Northern Uganda may increase further. This study, therefore, determined the knowledge and attitude of the community, medical and veterinary workers regarding brucellosis and identified their practices.

\section{Methods}

\section{Ethical approval}

Ethical approval was obtained from Gulu University Research Council (Ref No: GU/ IRC/02/07/13) and the Uganda National Council of Science and Technology Reference No: HS 1442. Written consent was sought from all individuals before enrollment into the study.

\section{Study area, participant selection and data collection tool deveopment}

A cross-sectional study was conducted in post-conflict areas of Northern Uganda in the districts of Apac, Gulu, Lira, and Pader from March 2014 to February 2015. The study involved 17 public (not for profit) and private (for profit) out of the 244 health facilities present in the study districts [20-23]. The selection was based on capacity to test for brucellosis and willingness to participate in the study. The study targeted patients with fever, headache, joint pain, malaise, backache, fatigue, and loss of appetite visiting study health facilities. Medical personnel in the outpatient department (OPD) identified suspects and tested them with the rapid Brucella plate agglutination test. Patients with positive samples were enrolled for this study. Medical worker participants were staff in the OPD of the study health facilities including nurses, laboratory technicians, clinicians, and medical doctors. The study involved veterinary workers including willing veterinary doctors, animal husbandry officers, and veterinary assistants at the study district veterinary offices. All the participants were briefed on the study objectives and willing respondents signed consent form before enrollment.

The questionnaire was developed drawing experience from studies elsewhere [10]. Each target group had specific questions on knowledge, attitude, and practices. The questionnaires had both close- and open-ended question(s). Knowledge on transmission pathways and symptoms for brucellosis in humans and animals were sought. While attitude regarding brucellosis was determined by assessing the feelings of respondents about the importance of brucellosis, need to test for brucellosis and educate the community on causes, transmission, symptoms, and control of brucellosis. To identify practices, patients answered questions on consumption of animal products and handling of suspected infectious materials. Information sought from medical workers included routine brucellosis testing and availability of test reagents at health facilities, and veterinary workers answered questions on the use of protective wear during animal examination and treatment. The questionnaire was pre-tested within the study area to assess clarity, logical sequencing of questions, and required time for completion. The questionnaire was filled by the participants who signed consent form and trained interpreters guided respondents who could not speak English. $30 \mathrm{~min}$ were allocated to complete and the questionnaire was retrieved immediately to avoid discussion and reference to other materials.

A participant was considered "knowledgeable" if stated three or more (out of five correct) pathways for brucellosis transmission in animals and humans and "poorly knowledgeable" if listed less than three. The participants who stated four or more clinical symptoms in animals and 10 or more in humans were regarded as "knowledgeable" and "poorly knowledgeable" if stated less. "Good/positive" attitude was considered if a participant agreed or strongly agreed with the provided questions about the importance of brucellosis, the need to test and educate the community on causes, transmission, symptoms, and control of brucellosis. "Good practice" for patients was considered if suspected materials were handled with protective gear and if consumed pasteurized milk products. "Good practice" for medical workers was considered if test reagents were available and routinely tested patients for brucellosis. While, "good practice" for veterinary workers was considered if a full protective gear (gum boots, gloves, overall) was worn while handling animals.

\section{Statistical analaysis}

Data were analyzed with SPSS (Version 16) using descriptive statistics. Categorical variables were presented as proportions. Finally, the effect of sociodemographic characteristics on knowledge, attitude, and practices was assessed using Chi-square test at $5 \%$ significance interval.

\section{Results}

\section{Participants' knowledge regarding brucellosis}

A total of 251 patients aged 10-84 years (mean - 36.9, standard deviation - 13.9) fulfilled the criteria for determining the level of knowledge among the community regarding brucellosis. Up to $53.4 \%(134 / 251)$ of participants were female and only $39.4 \%(99 / 251)$ of study patients had attained education beyond primary level. Although many (63.3\%) of the participants had heard of brucellosis, only $8 \%$ (20/251) were knowledgeable on methods for brucellosis transmission and symptoms (Table-1). The participants' overall knowledge on brucellosis differed statistically significantly with age $(\mathrm{p}=0.014)$ and level of education $(\mathrm{p}=0.001)$ but not with gender. The number of patients with poor knowledge on brucellosis 
was higher for participants with education above primary level than those below.

In total, 59 health workers participated in the study and $86.4 \%$ were males, $11.9 \%$ had bachelor degrees, and only $8.5 \%$ were medical doctors. Furthermore, $37.3 \%$ were laboratory technicians (1 female, 21 male), $33.9 \%$ were clinical officers ( 1 female, 20 male), and $20.3 \%$ were nurses ( 6 female, 6 male). The age of the health workers ranged from $33-56,25-53,22-43$, and 23-51 for medical doctors, clinical officers, laboratory technicians, and nurses, respectively. Only $15.3 \%$ (9/59) of medical workers were knowledgeable on methods of transmission and symptoms of brucellosis (Table-1). Knowledge of medical workers differed statistically significantly with the level of education $(\mathrm{p}<0.001)$ and occupation $(p<0.001)$. However, knowledge levels regarding brucellosis did not differ with age and gender of medical workers.

A total of 28 veterinary workers participated in the study. Only $7.1 \%$ were females and overall $60.7 \%$ were aged between 21 and 30 years. $75 \%$ were diploma holders working as animal husbandry officers, $17.9 \%$ certificate holders, designated as veterinary assistants and only $7.1 \%$ degree holders designated as veterinary doctors. Only $21.4 \%(6 / 28)$ of veterinary workers

Table-1: Relationship of education, occupation, age, and gender with patients' and medical/veterinary workers' knowledge and attitude regarding brucellosis.

\begin{tabular}{|c|c|c|c|c|c|c|c|c|}
\hline \multirow[t]{2}{*}{ Variable } & \multicolumn{2}{|c|}{ Frequency (\%) } & \multirow[t]{2}{*}{$\chi^{2}$} & \multirow[t]{2}{*}{ p value } & \multicolumn{2}{|c|}{ Frequency (\%) } & \multirow[t]{2}{*}{$\chi^{2}$} & \multirow[t]{2}{*}{ p value } \\
\hline & $\begin{array}{c}\text { Poor } \\
\text { knowledge }\end{array}$ & Knowledgeable & & & $\begin{array}{l}\text { Poor } \\
\text { attitude }\end{array}$ & $\begin{array}{l}\text { Good } \\
\text { attitude }\end{array}$ & & \\
\hline \multicolumn{9}{|c|}{ Participants $(n=251)$} \\
\hline Gender & & & 0.02 & 0.88 & & & 0.15 & 0.7 \\
\hline Male & $108(92.3)$ & $9(7.7)$ & & & $18(15.4)$ & $99(84.6)$ & & \\
\hline Female & $123(91.8)$ & $11(8.2)$ & & & $23(17.2)$ & $111(82.8)$ & & \\
\hline Qualification & & & 11.5 & $0.001 *$ & & & 0.98 & 0.32 \\
\hline$\leq$ Primary & $147(96.7)$ & $5(3.3)$ & & & $22(14.5)$ & $130(85.5)$ & & \\
\hline > Primary & $84(84.8)$ & $15(15.2)$ & & & $19(19.2)$ & $80(80.8)$ & & \\
\hline Age group & & & 10.6 & $0.014^{*}$ & & & 1.75 & 0.63 \\
\hline$<18$ years & $8(100)$ & $0(0)$ & & & $1(12.5)$ & $7(87.5)$ & & \\
\hline $18-44$ years & $178(94.7)$ & $10(5.3)$ & & & $29(15.4)$ & $159(84.6)$ & & \\
\hline $45-64$ years & $34(82.9)$ & $7(17.1)$ & & & $7(17.1)$ & $34(82.9)$ & & \\
\hline$\geq 65$ years & $11(78.6)$ & $3(21.4)$ & & & $4(28.6)$ & $10(71.4)$ & & \\
\hline \multicolumn{9}{|c|}{ Medical workers $(n=59)$} \\
\hline Qualification & & & 17.9 & $<0.001^{*}$ & & & 11 & $0.012 *$ \\
\hline Certificate & $22(100)$ & $0(0)$ & & & $0(0)$ & $22(100)$ & & \\
\hline Diploma & $25(86.2)$ & $4(13.8)$ & & & $0(0)$ & $29(100)$ & & \\
\hline Bachelor & $2(40)$ & $13(60)$ & & & $1(20)$ & $4(80)$ & & \\
\hline Postgraduate & $1(33.3)$ & $2(67.7)$ & & & $0(0)$ & $3(100)$ & & \\
\hline Occupation & & & 19 & $<0.001 *$ & & & 11 & $0.012 *$ \\
\hline Clinical officer & $17(85)$ & $3(15)$ & & & $0(0)$ & $20(100)$ & & \\
\hline $\begin{array}{l}\text { Laboratory } \\
\text { technologist }\end{array}$ & $20(90.9)$ & $2(9.1)$ & & & $0(0)$ & $22(100)$ & & \\
\hline Nurse & $12(100)$ & $0(0)$ & & & $0(0)$ & $12(100)$ & & \\
\hline Doctor & $1(20)$ & $4(80)$ & & & $1(20)$ & $4(80)$ & & \\
\hline Age group & & & 2.92 & 0.4 & & & 11 & $0.012 *$ \\
\hline $21-30$ years & $22(88)$ & $3(12)$ & & & $0(0)$ & $25(100)$ & & \\
\hline $31-40$ years & $15(83.3)$ & $3(16.7)$ & & & $0(0)$ & $18(100)$ & & \\
\hline $41-50$ years & $10(90.9)$ & $1(9.1)$ & & & $0(0)$ & $11(100)$ & & \\
\hline$>51$ years & $3(60)$ & $2(40)$ & & & $1(20)$ & $4(80)$ & & \\
\hline Gender & & & 1.67 & 0.2 & & & 0.16 & 0.69 \\
\hline Male & $42(82.4)$ & $9(17.6)$ & & & $1(2)$ & $50(98)$ & & \\
\hline Female & $8(100)$ & $0(0)$ & & & $0(0)$ & $8(100)$ & & \\
\hline \multicolumn{9}{|l|}{$\begin{array}{l}\text { Veterinary } \\
\text { personnel }(n=28)\end{array}$} \\
\hline Qualification & & & 8.77 & $0.012 *$ & & & - & - \\
\hline Certificate & $5(100)$ & $0(0)$ & & & $0(0)$ & $5(100)$ & & \\
\hline Diploma & $17(81)$ & $4(19)$ & & & $0(0)$ & $21(100)$ & & \\
\hline Bachelor & $0(0)$ & $2(100)$ & & & $0(0)$ & $2(100)$ & & \\
\hline Age group & & & 1.91 & 0.59 & & & - & - \\
\hline $21-30$ years & $13(78.5)$ & $4(23.5)$ & & & $0(0)$ & $17(100)$ & & \\
\hline $31-40$ years & $4(66.7)$ & $2(33.3)$ & & & $0(0)$ & $11(100)$ & & \\
\hline $41-50$ years & $1(100)$ & $0(0)$ & & & & & & \\
\hline >51 years & $4(100)$ & $0(0)$ & & & & & & \\
\hline Gender & & & 0.59 & 0.44 & & & - & - \\
\hline Male & $20(76.9)$ & $6(23.1)$ & & & $0(0)$ & $26(100)$ & & \\
\hline Female & $2(100)$ & $0(0)$ & & & $0(0)$ & $2(100)$ & & \\
\hline
\end{tabular}

*Significant at $5 \%$ 
were knowledgeable on transmission and symptoms of brucellosis (Table-1). The knowledge regarding brucellosis among veterinary workers differed with level of education $(p=0.012)$. However, no difference in knowledge levels was observed among the different age groups. Similarly, no difference in knowledge was observed between female and male veterinary workers ( $>00.05)$.

\section{Attitude of participants regarding brucellosis}

Positive attitude regarding brucellosis control and prevention was recorded in $83.7 \%(210 / 251)$ of participants and did not differ with level of education, gender, and age ( $>00.05)$. Almost all medical workers (98\%) who participated in the study had a positive attitude regarding brucellosis. However, one male medical doctor aged over 51 had a negative attitude. All veterinary workers had a good attitude about brucellosis, particularly in regard to the importance, testing, and sensitizing communities. There was no difference in attitude observed among age groups, education level, and gender of veterinary workers (Table-1).

\section{Participants' practices regarding brucellosis}

Only $17.1 \%$ of participants consumed pasteurized milk products and just $6.8 \%$ of handled aborted materials with protective wear (Table-2). Only 8\% $(20 / 251)$ of participants observed at least two of the good practices regarding brucellosis. Patients' practices differed statistically significantly with education level $(p=0.004)$ and gender $(p=0.043)$. More male patients had poor practices regarding brucellosis than females and more patients who attained above primary school education had good practices compared to those with lower education level (Table-3). While $44.1 \%$ of the medical workers reported the availability of reagents and equipment at health facilities and only $33.9 \%$ of specified testing for brucellosis (Table-2). However, only $13.6 \%$ of medical workers indicated both testing and availability of reagents and equipment for brucellosis at health facilities which was considered as good practice in this study. Medical workers' practices did not differ with level of education, occupation, age, and sex (Table-3).
In addition, $<7 \%$ of the veterinary workers wore full protective gears (gloves, gum boots, and overalls) while handling animals. The good practices among veterinary workers differed statistically significantly with level of education $(p<0.001)$. Good practices were observed more in the highly educated veterinarians than those with low qualifications (Table-3).

\section{Discussion}

This is the first study to assess knowledge, attitude, and practices of the community, medical and veterinary workers in Northern Uganda. Knowledge of brucellosis transmission and symptoms in humans and animals across the study groups was poor. The participants' knowledge on brucellosis differed statistically significantly with level of education $(p=0.001)$. The number of patients with poor knowledge on brucellosis was higher for participants with education above the primary level than those below. This finding, however, points to a serious risk to communities in North Uganda whose literacy levels are low compared to other regions in the country. The Uganda National Household Survey 2012/13 reported Northern Uganda had the least number (3.1\%) of persons aged $\geq 15$-year-old with education level above secondary. As well, the region had the highest number $(26.4 \%)$ of population with no formal schooling compared to $11.7 \%$ in central, $16.1 \%$ in eastern, and $20.0 \%$ in Western Uganda [24]. The education status of this region is not surprising since northern Uganda was under decades of violence and instability which left the education system devastated causing the region to have the least educated people. In addition, this study showed that participants aged 45 years and more had better knowledge regarding brucellosis than those below. This finding agrees with a recent study in Uganda where high knowledge regarding brucellosis was observed in persons above 45-year-old [15]. This could be due to accumulation in experience and insights about the disease that occurs with age.

Health workers in Northern Uganda also had poor knowledge on transmission and clinical presentation of brucellosis. However, the knowledge among this

Table-2: Practices of patients, medical and veterinary workers regarding brucellosis.

\begin{tabular}{|c|c|c|c|c|c|c|}
\hline \multirow[t]{2}{*}{ Good practices } & \multicolumn{2}{|c|}{ Patients } & \multicolumn{2}{|c|}{ Medical workers } & \multicolumn{2}{|c|}{ Veterinary workers } \\
\hline & $\begin{array}{l}\text { Frequency } \\
(n-251)\end{array}$ & $\begin{array}{l}\text { Proportion } \\
(\%)\end{array}$ & $\begin{array}{l}\text { Frequency } \\
(n=59)\end{array}$ & $\begin{array}{l}\text { Proportion } \\
(\%)\end{array}$ & $\begin{array}{l}\text { Frequency } \\
(n=28)\end{array}$ & $\begin{array}{l}\text { Proportion } \\
(\%)\end{array}$ \\
\hline Vaccinating animals & 16 & 6.4 & - & - & - & - \\
\hline Hygienic handling of aborted material & 17 & 6.8 & - & - & - & - \\
\hline Consumption of pasteurized milk products & 43 & 17.1 & & - & - & - \\
\hline Test for brucellosis & - & - & 20 & 33.9 & - & - \\
\hline Availability of reagent and equipment & - & - & 26 & 44.1 & - & - \\
\hline \multicolumn{7}{|l|}{$\begin{array}{l}\text { Testing and availability of reagent and } \\
\text { equipment for }\end{array}$} \\
\hline Brucellosis & - & - & 8 & 13.6 & - & - \\
\hline Wear all (gum boots, gloves, overall) & - & - & - & - & 2 & 7.1 \\
\hline Wear gloves & - & - & - & - & 3 & 10.7 \\
\hline Wear gumboots & - & - & - & - & 14 & 50.0 \\
\hline Wear overall & - & - & - & - & 9 & 32.1 \\
\hline
\end{tabular}


Table-3: Relationship of education, occupation, age, and gender with patients' and medical/veterinary workers' practices regarding brucellosis.

\begin{tabular}{|c|c|c|c|c|}
\hline \multirow[t]{2}{*}{ Variables } & \multicolumn{2}{|c|}{ Frequency (\%) } & \multirow[t]{2}{*}{$\chi^{2}$} & \multirow[t]{2}{*}{ p value } \\
\hline & Poor practices & Good practices & & \\
\hline \multicolumn{5}{|l|}{ Patient participants $(n=251)$} \\
\hline Gender & & & 4.1 & $0.043 *$ \\
\hline Male & $112(95.7)$ & $5(4.3)$ & & \\
\hline Female & $119(88.8)$ & $15(11.2)$ & & \\
\hline Qualification & & & 8.5 & $0.004 *$ \\
\hline$\leq$ Primary & $146(95.4)$ & $6(4.6)$ & & \\
\hline >Primary & $85(86.9)$ & $14(13.1)$ & & \\
\hline Age group & & & 5.7 & 0.13 \\
\hline$<18$ years & $6(75)$ & $2(25)$ & & \\
\hline $18-44$ years & $175(93.1)$ & $13(6.9)$ & & \\
\hline $45-64$ years & $36(87.8)$ & $5(12.2)$ & & \\
\hline$\geq 65$ years & $14(100)$ & $0(0)$ & & \\
\hline \multicolumn{5}{|l|}{ Medical workers $(n=59)$} \\
\hline Qualification & & & 5.5 & 0.14 \\
\hline Certificate & $21(95.5)$ & $1(4.5)$ & & \\
\hline Diploma & $25(86.2)$ & $4(13.8)$ & & \\
\hline Bachelor & $3(60)$ & $2(40)$ & & \\
\hline Postgraduate & $2(67.7)$ & $1(33.3)$ & & \\
\hline Occupation & & & 3.7 & 0.3 \\
\hline Clinical officer & $17(85)$ & $3(15)$ & & \\
\hline Laboratory technologist & $20(90.9)$ & $2(9.1)$ & & \\
\hline Nurse & $11(91.7)$ & $1(8.3)$ & & \\
\hline Doctor & $3(60)$ & $2(40)$ & & \\
\hline Age group & & & 0.6 & 0.9 \\
\hline $21-30$ years & $21(84)$ & $4(16)$ & & \\
\hline $31-40$ years & $16(89.9)$ & $2(11.1)$ & & \\
\hline $41-50$ years & $10(90.9)$ & $1(9.1)$ & & \\
\hline$>51$ years & $4(80)$ & $1(20)$ & & \\
\hline Gender & & & 1.5 & 0.23 \\
\hline Male & $43(84.3)$ & $8(15.7)$ & & \\
\hline Female & $8(100)$ & $0(0)$ & & \\
\hline \multicolumn{5}{|l|}{ Veterinary personnel $(n=28)$} \\
\hline Qualification & & & 28 & $0.000 *$ \\
\hline Certificate & $5(100)$ & $0(0)$ & & \\
\hline Diploma & $21(100)$ & $0(0)$ & & \\
\hline Bachelor & $0(0)$ & $2(100)$ & & \\
\hline Age group & & & 1.3 & 0.74 \\
\hline $21-30$ years & $16(94.3)$ & $1(5.7)$ & & \\
\hline $31-40$ years & $5(83.3)$ & $1(16.7)$ & & \\
\hline $41-50$ years & $1(100)$ & $0(0)$ & & \\
\hline$>51$ years & $4(100)$ & $0(0)$ & & \\
\hline Gender & & & 0.2 & 0.68 \\
\hline Male & $24(92.3)$ & $2(7.7)$ & & \\
\hline Female & $2(100)$ & $0(0)$ & & \\
\hline
\end{tabular}

*Significant at $5 \%$

group differed significantly with occupation and level of education. The nurses were the least and the doctors were the most knowledgeable about brucellosis. This situation is appalling since in Uganda, health centers II and III, which are very close to the communities, are entirely managed by nurses. It could be possible that some patients who visit these health facilities suffer from brucellosis but with the absence of doctors, proper diagnosis, and treatment of the disease could be hampered. Only, $21.4 \%$ of veterinary workers were knowledgeable in regard to transmission and symptoms of brucellosis. This finding parallels a study in Nigeria and could be attributed to their professional training [25]. In general, veterinary workers are thought to be knowledgeable on issues of brucellosis owing to their professional training. However, such poor knowledge among veterinary workers in this study points to brucellosis being a neglected disease in Uganda thus its importance not probably emphasized during professional trainings in the country.

Interestingly, this study revealed a positive attitude among all study groups. This finding provides an opportunity for community education. However, the good attitude did not translate into good practices across all the study groups. The bad practices recorded in this study are a great risk for human infection. Many participants engaged in bad practices, not surprising though since Northern Uganda is ranked as the poorest [26]. Reports elsewhere show that poor people live closer to their animals and are prone to 
consuming unpasteurized milk, poorly prepared meat from infected animals and lack access to protective gears for handling aborted or full-term parturition wastes [27]. This also confirms an earlier study which reported irregular brucellosis screening due to the inconsistent supply of test reagents and kits in a major hospital in Uganda [16]. The absence of test kits at health facilities may indicate brucellosis is a neglected disease in Uganda. Similarly, only $7.1 \%$ of veterinary workers engaged in good practices. This finding is in agreement with a study elsewhere, which reported that the positive attitude, and the good knowledge of veterinarians did not translate into good practices [10].

Since the current study dealt with only suspected brucellosis patients and did not cover all health facilities for spatial analyses, the results from this study have to be interpreted cautiously. Nevertheless, this study provides valuable information to support programs for control of brucellosis.

\section{Conclusion}

Knowledge and practices regarding brucellosis were poor among all study groups but attitude was good. Education was shown to positively influence knowledge and practices. There is an opportunity to improve brucellosis control through continuous training on issues relating to the disease among key actors. Studies to determine the prevalence and local factors for brucellosis occurrence could provide valuable information in the development of cost-effective strategies to minimize disease risk exposure.

\section{Authors' Contributions}

HMN was involved in the development of the concept, study design, data collection, analysis, and writing of the paper. JE and DOO helped to develop the concept, supervised the study, and critically revised the paper. GWN participated in the study design and data interpretation, revised the paper and approved the final version. JMK participated in the acquisition of the data, revised the paper and approved the final version. DO and $\mathrm{JN}$ participated in the development of the concept study design and the drafting and final revision of the paper. All authors read and approved the final version of the paper.

\section{Acknowledgments}

This work was supported by Gulu University Enhancing Capacity for Agricultural Research and Training in Gulu University project [grant numbers NICHE-UGA 083]; funded by Netherlands Government through Netherlands Organization for Capacity Building in Higher Education (NUFFIC) and to International Centre for Development Oriented Research in Agriculture (ICRA), Netherlands, which managed the funds.

\section{Competing Interests} interests.

The authors declare that they have no competing

\section{References}

1. Abubakar M, Mansoor M, Arshed M. Bovine brucellosis: Old and new concepts with Pakistan perspective. Pak Vet J 2011;32:147-55.

2. Schelling E, Diguimbaye C, Daoud S, Nicolet J, Boerlin P, Tanner M, et al. Brucellosis and Q-fever seroprevalences of nomadic pastoralists and their livestock in Chad. Prev Vet Med 2003;61:279-93

3. FAO. Brucella Melitensis in Eurasia and the Middle East. FAO Animal Production and Health Proceedings. Vol. 10; 2010. p. 1-47.

4. Mantur BG, Amarnath SK, Shinde SR. Review of clinical and laboratory features of human brucellosis. Vet Microbiol 2007;25:188-202.

5. Moreno E, Cloeckaert A, Moriyón I. Brucella evolution and taxonomy. Vet Microbiol 2002;90:209-27.

6. Corbel MJ. Brucellosis in humans and animals brucellosis in humans and animals. World Health Organization in Collaboration with the Food and Agriculture Organization of the United Nations. Geneva, Switzerland: World Organization for Animal Health; 2006. p. 7, 89 .

7. Sayyad S, Malak MM, Miri BA, Gharib SM, Vahabi A. The prevalence rate of human brucellosis in Sanandaj county, West of Iran. Life Sci J 2014;11:23-5.

8. Mantur BG, Mulimani MS, Bidari LH, Akki AS, Tikare NV. Bacteremia is as unpredictable as clinical manifestations in human brucellosis. Int J Infect Dis 2008;12:303-7.

9. Smits HL, Cutler SJ. Contributions of biotechnology to the control and prevention of brucellosis in Africa. Afr J Biotechnol 2004;3:631-6.

10. Howyida SA, Lamiaa TA, Kamel AZ. Awareness of personnel in direct contact with animals regarding brucellosis. J Am Sci 2012;8:790-6.

11. Lindahl E, Sattorov N, Boqvist S, Magnusson U. A study of knowledge, attitudes and practices relating to brucellosis among small-scale dairy farmers in an urban and peri-urban area of Tajikistan. PLoS One 2015;10:e0117318.

12. Seleem MN, Boyle SM, Sriranganathan N. Brucellosis: A re-emerging zoonosis. Vet Microbiol 2010;140:392-8.

13. Galukande M, Muwazi S, Mugisa DB. Aetiology of low back pain in Mulago Hospital, Uganda. Afr Health Sci 2005;5:164-7.

14. Kyebambe PS. Acute Brucella meningomyeloencephalo - Spondylosis in a teenage male. Afr Health Sci 2005;5:69-72.

15. Kansiime C, Mugisha A, Makumbi F, Mugisha S, Rwego IB, Sempa J, et al. Knowledge and perceptions of brucellosis in the pastoral communities adjacent to Lake Mburo National Park, Uganda. BMC Public Health 2014;14:242.

16. Makita K, Fèvre EM, Waiswa C, Kaboyo W, Eisler MC, Welburn SC. Spatial epidemiology of hospital-diagnosed brucellosis in Kampala, Uganda. Int $\mathrm{J}$ Health Geogr 2011;10:1-9.

17. Kozukeev TB, Ajeilat S, Maes E, Favorov M. Risk factors for brucellosis - Leylek and Kadamjay districts, Batken Oblast. MMWR Morb Mortal Wkly Rep 2003;86:31-4.

18. Wojno JM, Moodley C, Pienaar J, Beylis N, Jacobsz L, Nicol MP, et al. Human brucellosis in South Africa: Public health and diagnostic pitfalls. S Afr Med J 2016;106:883-5.

19. Chipwaza B, Mugasa JP, Mayumana I, Amuri M, Makungu C, Gwakisa PS. Community knowledge and attitudes and health workers' practices regarding non-malaria febrile illnesses in Eastern Tanzania. PLoS Negl Trop Dis 2014;8:e2896.

20. Apac District Local Government. Apac Statistical Abstract. Uganda Bureau of Statistics Kampala Uganda, UBOS. District Local Government Statistical Abstract; 2012, June. p. 26-31.

21. Uganda Bureau of Statistics. Gulu District Local Government. Gulu Statistical Abstract. Kampala, Uganda: Uganda Bureau of Statistics; 2013. p. 60-70. 
22. Uganda Bureau of Statistics. Lira District Local Government. Lira Statistical Abstract. Kampala, Uganda: Uganda Bureau of Statistics; 2012. p. 20-31.

23. Uganda Bureau of Statistics. Pader District Local Government. Pader Statistical Abstract. Kampala, Uganda: Uganda Bureau of Statistics; 2009. p. 10-4.

24. UBOS. Uganda National Household Survey 2012/13. Kampala, Uganda: Uganda Bureau of Statistics; 2014. p. $97,98$.

25. Adesiji YO, Adesiji GB, Fagabami AH. Brucellosis:
Knowledge, attitude and practices among occupationall exposed indviduals in Osun state. Sci Focus 2005;10:38-41.

26. Ministry of Finance, Planning and Economic Development. The Republic of Uganda Poverty Status Report. Kampala, Uganda: Economic Development Policy and Research Department; 2014. p. 58, 64.

27. Grahn C. Brucellosis in Small Ruminants - An Investigation of Knowledge, Attitude and Practices in Peri-Urban Farming Around the Region of Dushanbe, Tajikistan. Vol. 16528697. Uppsala; 2013. p. 1-22.

$* * * * * * * *$ 